\title{
Conservação de soro do leite integral bovino e sua influência na alimentação de leitões na fase de creche
}

\author{
Milena Alves da Silva ${ }^{1}$, Adryze Gabrielle Dorásio ${ }^{2}$, Jean Kaique Valentim ${ }^{3}$, Janaína Palermo Mendes ${ }^{4}$, Jeferson \\ Eder Ferreira de Oliveira ${ }^{5}$, Sabrina Vargas Monteiro ${ }^{6}$, Bruna Pontara Villas Boas Ribeiro ${ }^{7}$, Juliano José de \\ Oliveira Coutinho ${ }^{8}$, Ariadne Freitas Silva ${ }^{9}$
}

DOI: https://doi.org/10.35699/2447-6218.2021.26778

\begin{abstract}
Resumo
Objetivou-se demonstrar a melhor forma de conservação do soro de leite e verificar o desempenho de suínos na fase de creche utilizando diferentes níveis de soro de leite em substituição a dieta basal. Foram utilizados 30 leitões machos da linhagem DanBred x Large White, com peso médio de $6 \mathrm{~kg} \pm 0,200 \mathrm{~g}$ com 23 dias de idade. Os animais foram distribuídos em cinco grupos com inclusão do soro do leite integral bovino. Estes tratamentos foram realizados de acordo com a inclusão do soro de leite na ração controle, com 6 repetições por tratamento em delineamento inteiramente casualizado: D0- Dieta testemunha sem soro; D1 - substituição de 7\% da dieta D0 por soro de leite; D2 - substituição de $14 \%$ da D0 por soro de leite; D3 - substituição de $21 \%$ da dieta D0 por soro de leite; D4 - substituição de $28 \%$ da dieta D0 por soro de leite. Os parâmetros avaliados quanto a qualidade do soro de leite foram a acidez em graus dornic ( $\left.{ }^{\circ} \mathrm{D}\right)$ e com relação ao desempenho animal foram, consumo de ração, conversão alimentar, ganho de peso médio diário. Os resultados foram submetidos à análise de variância e realizado o teste de Tukey ao nível de $5 \%$. O melhor método de conservação do soro de leite é mantê-lo resfriado por até uma semana. A utilização do soro de leite integral em dietas de leitões na fase de creche é viável até 7\%, pois apesar de aumentar o consumo de ração, melhora a conversão alimentar e consequentemente o desempenho animal.
\end{abstract}

Palavras-chave: Desempenho. Leitegada. Produto lácteo. Suinocultura.

\section{Conservation of whole bovine milk serum and its influence on piglet feeding in the nursery phase}

\footnotetext{
Abstract

${ }^{1}$ Instituto Federal de Minas Gerais. Campus Bambuí . Bambuí, MG. Brasil. http://orcid.org/0000-0003-1127-4894

${ }^{2}$ Instituto Federal de Minas Gerais. Campus Bambuí . Bambuí, MG. Brasil. http://orcid.org/0000-0003-1998-0099

${ }^{3}$ Universidade Federal da Grande Dourados. Dourados. Dourados, MS. Brasil. http://orcid.org/0000-0001-8547-4149

${ }^{4}$ Universidade Federal da Grande Dourados. Dourados. Dourados, MS. Brasil. https://orcid.org/0000-0002-7860-0933

5Instituto Federal de Minas Gerais. Campus Bambuí. Bambuí, MG. Brasil. http://orcid.org/0000-0003-3729-9053

${ }^{6}$ Instituto Federal de Minas Gerais. Campus Bambuí. Bambuí, MG. Brasil. http://orcid.org/0000-0002-2505-5265

${ }^{7}$ Instituto Federal de Minas Gerais. Campus Bambuí. Bambuí, MG. Brasil. http://orcid.org/0000-0003-3386-191

${ }^{8}$ Instituto Federal de Minas Gerais. Campus Bambuí. Bambuí, MG. Brasil. http://orcid.org/0000-0002-7481-6366

${ }^{9}$ Universidade Estadual de Montes Claro. Campus Janaúba. Janaúba, MG. Brasil.

http://orcid.org/0000-0003-4378-4733

*Autor para correspondência: kaique.tim@hotmail.com
}

Recebido para publicação em 20 de dezembro de 2020. Aceito para publicação em 12 de fevereiro de 2021. e-ISSN: 2447-6218 / ISSN: 2447-6218. Atribuição CC BY. 
Silva, M. A. et al.

The objective was to demonstrate the best way to preserve whey and to verify the performance of pigs in the nursery phase using different levels of whey to replace the basal diet. Forty DanBred x Large White male piglets were used, with an average weight of $6 \mathrm{~kg} \pm 0,200 \mathrm{~g}$ at 23 days of age. The animals were divided into five groups with the inclusion of whole bovine milk serum. These treatments were performed according to the inclusion of whey in the control diet, with 8 replicates per treatment in a completely randomized design: D0- Control diet without serum; D1 - replacement of $7 \%$ of the D0 diet by whey; D2 - replacement of $14 \%$ of D0 by whey; D3 - replacement of $21 \%$ of the D0 diet by whey; D4 - replacement of $28 \%$ of the D0 diet by whey. The parameters evaluated for the quality of whey were acidity in Dornic degrees, and about the animal, the performance was feed intake, feed conversion, average daily weight gain. The results were subjected to analysis of variance and the Tukey test was performed at the $5 \%$ level. The best method of preserving whey is to keep it cold for up to a week. The use of whole whey in piglet diets in the nursery phase is viable up to $7 \%$ because despite increasing feed consumption, it improves feed conversion and consequently animal performance.

Keywords: Dairy product. Performance. Piglets. Pig farming.

\section{Introdução}

A suinocultura visando principalmente o aumento de produtividade e redução dos custos de produção passou por diversas alterações tecnológicas, isso porque a alimentação ainda continua sendo o componente de maior participação no custo de produção (Barros et al., 2020; Almeida et al., 2020). O consumo de ração do leitão na fase de creche representa apenas $2,6 \%$ do total de ração sólida até o abate, no entanto, necessita de uma escolha cuidadosa na formulação correta das rações, e também, na correta mistura dos ingredientes. A busca por alimentos alternativos que visem à redução dos custos de produção tem sido constante, assim, o soro do leite tem se mostrado eficiente (Zardo e Lima, 1999; Haraguchi et al., 2006).

O soro é o líquido resultante da separação da caseína e da gordura do leite no processo de elaboração do queijo, apresentando alto valor nutricional, com mais da metade dos sólidos presentes no leite integral original, incluindo a maior parte da lactose, minerais e vitaminas hidrossolúveis e cerca de $20 \%$ das proteínas do leite, o soro de leite pode ser fornecido aos leitões na sua forma natural líquida. Além disso, possui carboidratos como a lactose, nitrogênio das proteínas, além de ser uma fonte de cálcio, as proteínas do soro do leite possuem propriedades antioxidantes, (Matalanis et al., 2012; Almeida et al., 2015).

O soro do leite é originado da coagulação do leite, sendo um subproduto capaz de atender tanto a alimentação humana quanto a animal, desta forma, é necessária a busca por alternativas que visem à utilização correta deste coproduto, já que alguns subprodutos gerados podem ocasionar problemas para o meio ambiente quando desperdiçados em grandes volumes, sendo constituinte das águas residuais advindas dos lacticínios e direcionadas diretamente aos corpos receptores ou em sistemas de tratamento com baixa eficiência, contaminando drasticamente o meio ambiente, caracterizando grave impacto negativo das indústrias de laticínios no mundo (Garrido et al., 2016; Ganju e Gogate, 2017).
Após o desmame, a composição da dieta dos leitões altera drasticamente, sendo o leite da porca substituído por uma dieta com maior nível de matéria seca, a lactose pelo amido, e a caseína do leite (de alto valor biológico) por proteínas vegetais menos digestíveis para o leitão (Caldara et al., 2009), associado muitas vezes a problemas de hipersensibilidade no trato gastrointestinal.

Tais mudanças na dieta possuem ações diretas na queda do desempenho após o desmame, em função dos problemas advindos da imaturidade fisiológica do trato gastrointestinal frente ao novo alimento (Haraguchi et al., 2006; Xiao et al., 2016; Navis et al., 2020a). Assim, a inclusão de lactose na dieta promove um ecossistema gastrointestinal saudável de suínos após o desmame em termos da manutenção de algumas espécies de Lactobacillus no trato gastrointestinal (Sugiharto et al., 2015). Dietas com produtos lácteos podem melhorar a taxa de crescimento de leitões, desta forma há produtos derivados do leite conhecidos como o soro de leite, que é um subproduto da fabricação do queijo, que pode ser utilizado na alimentação de suínos (Navis et al., 2020b).

Com isso, este trabalho teve como objetivo mostrar o melhor método de conservação do soro de leite e avaliar o desempenho dos suínos na fase de creche utilizando diferentes níveis de soro de leite bovino na dieta.

\section{Material e métodos}

O experimento foi realizado no setor de Suinocultura do Instituto Federal de Minas Gerais campus Bambuí. Foram utilizados 30 leitões machos da linhagem DanBred x Large White, com peso médio de $6 \mathrm{~kg} \pm 0,200 \mathrm{~g}$ com 23 dias de idade. Os animais foram alojados em baias elevadas com 1,3 x 1,1 x 0,6 m, com piso parcialmente ripado, bebedouro tipo chupeta e comedouro manual. Para o fornecimento de calor suplementar foram utilizadas lâmpadas, a aeração interna foi controlada por sistema de cortinas, mantendo a temperatura entre $23^{\circ} \mathrm{C}$ e $28^{\circ} \mathrm{C}$. 
Conservação de soro do leite integral bovino e sua influência na alimentação de leitões na fase de creche

Os animais foram distribuídos em cinco grupos distintos com inclusão do soro do leite integral bovino, desta forma, estes tratamentos foram realizados de acordo com a inclusão do soro de leite na ração controle, com 6 repetições por tratamento em delineamento inteiramente casualizado (DIC) : D0- Dieta testemunha sem soro; D1 - substituição de $7 \%$ da dieta D0 por soro de leite; D2 - substituição de $14 \%$ da D0 por soro de leite;
D3 - substituição de $21 \%$ da dieta D0 por soro de leite; D4 - substituição de $28 \%$ da dieta D0 por soro de leite.

A dieta base foi elaborada com milho e farelo de soja e formuladas de acordo com Rostagno et al. (2011) conforme a (Tabela 1). A alimentação foi fornecida duas vezes ao dia pela manhã às 09:00 h e pela tarde às 15:00 h.

Tabela 1 - Formulação e composição química da ração base dos leitões (Inicial).

\begin{tabular}{lccccccc}
\hline Ingredientes & Porcentual & PB (\%) & $\begin{array}{c}\text { EM (kcal/ } \\
\mathbf{k g})\end{array}$ & Ca (\%) & $\begin{array}{c}\text { P total } \\
(\%)\end{array}$ & Lis (\%) & Met+Cist \\
\hline Milho & 61,7 & 5,09 & 2060,78 & 0,018 & 0,049 & 0,12 & 0,197 \\
\hline Farelo de soja & 28,3 & 12,8 & 797,96 & 0,068 & 0,051 & 0,72 & 0,33 \\
\hline Açúcar & 5,0 & ---- & 37,37 & ---- & ---- & --- & 0,065 \\
\hline Núcleo Inicial* & 5,0 & ---- & ---- & 0,5 & 0,24 & 0,02 \\
\hline Total & 100 & 17,89 & 2896,11 & 0,59 & 0,34 & 0,905 & 0,55 \\
\hline
\end{tabular}

*Níveis de garantia do núcleo vitamínico-mineral: Ácido pantotênico (min) $240 \mathrm{mg} / \mathrm{kg}$; ácido fosfórico (min) $864 \mathrm{mg} / \mathrm{kg}$; ácido fólico (min) 0,44 $\mathrm{mg} / \mathrm{kg}$; antioxidante (min) $200 \mathrm{mg} / \mathrm{kg}$; acidificante (min) $1500 \mathrm{mg} / \mathrm{kg}$; bacilus subtillis (min) 2,5 UFC/kg; bacilos lincheniforms (min) 2,5 UFC/kg; biotina (min) 0,4 mg/kg; cálcio (max) $30 \mathrm{~g} / \mathrm{kg}$; cálcio (min) $10 \mathrm{~g} / \mathrm{kg}$; cloro (min) $59 \mathrm{~g} / \mathrm{kg}$; cobre (min) $600 \mathrm{mg} / \mathrm{kg}$; colina (min) $1850 \mathrm{mg} / \mathrm{kg}$; enxofre (min) $5000 \mathrm{mg} / \mathrm{kg}$; ferro (min) $600 \mathrm{mg} / \mathrm{kg}$; flúor (max) $470 \mathrm{mg} / \mathrm{kg}$; flavorizante (min) $1300 \mathrm{mg} / \mathrm{kg}$; fosforo (min) g/kg; iodo (min) $3 \mathrm{mg} / \mathrm{kg}$; lactose (min) 100 g/kg; lisina (min) 18 g/kg; manganês (min) 200 mg/kg; metionina (min) 4000 mg/kg; niacina (min) 200 mg/kg; saccharomyces cerevise (min) 2 UFC/kg; selênio (min) 1,2.

O soro de leite integral foi fornecido pelo Setor de Laticínios do campus Bambuí, sendo conservado em refrigeração na temperatura de $8^{\circ} \mathrm{C}$, assim, foi feita análise de acidez para constatar a melhor forma de conservação do soro, sendo transportado até o setor de suinocultura o qual foi incluído à ração para o fornecimento aos leitões. Os parâmetros avaliados quanto à qualidade do soro de leite foram a acidez em graus Dornic e com relação ao desempenho animal, foram, consumo de ração $(\mathrm{kg})$, conversão alimentar e ganho de peso médio diário $(\mathrm{kg})$.

A conservação do soro foi realizada através de três métodos: o primeiro foi a conservação, onde o leite foi resfriado a $8^{\circ} \mathrm{C}$. O segundo foi a pasteurização lenta do soro do leite fresco à uma temperatura de $63^{\circ} \mathrm{C}$ por 30 minutos, logo após este processo o produto passou por um descanso até atingir a temperatura de $24^{\circ} \mathrm{C}$, e posteriormente foi encaminhado para a câmara fria para ser conservado a $8^{\circ} \mathrm{C}$. No terceiro método o soro foi pasteurizado e congelado, mantido a uma temperatura de $-2^{\circ} \mathrm{C}$.

Os dados de ganho médio diário de peso foram obtidos por pesagens individuais desde o início do experimento semanalmente até os 56 dias pós-desmame (8 semanas). O consumo diário de ração foi obtido pela quantidade de ração fornecida medida diariamente e no final de cada período, foi realizada uma totalização subtraindo as sobras presentes nos comedouros.

Os dados foram verificados quanto à normalidade dos resíduos utilizando-se o teste de Shapiro-Wilk e homogeneidade das variâncias com uso do teste de Levene.
Posteriormente, foram submetidos à análise de variância através do programa R Studio. Quando observado efeito significativo foram realizadas comparações de médias com uso do teste de Tukey. Para todas as análises realizadas o nível de significância utilizado foi de 5\%.

\section{Resultados e discussão}

Na primeira semana de avaliação, o soro pasteurizado, resfriado e pasteurizado/congelado mantiveram-se em $11^{\circ} \mathrm{D}$. Na segunda semana de análise, o soro do leite manteve-se em $11^{\circ} \mathrm{D}$, a conservação pasteurizada $\left(17^{\circ} \mathrm{D}\right)$, pasteurizado/congelado $\left(22^{\circ} \mathrm{D}\right)$. Na terceira semana, o soro resfriado $\left(16^{\circ} \mathrm{D}\right)$, pasteurizado $\left(21^{\circ} \mathrm{D}\right)$. E na quarta semana, o resfriado $\left(20^{\circ} \mathrm{D}\right)$. Desta forma, o soro pasteurizado/congelado obtiveram a acidez mais distante do padrão tido como o ideal, por este motivo sua análise foi suspensa após há primeira semana (Tabela 2).

A acidez do leite pode ser analisada através do teste de Dornic, na literatura (Rosa et al., 2017; Santos et al., 2020) o leite possui acidez normal entre 13 a $18^{\circ} \mathrm{D}$, assim, a acidez do soro é determinada por $2 / 3$ da acidez do leite, variando normalmente de 12 a $13^{\circ} \mathrm{D}$.

Por isso, o soro do leite pasteurizado e resfriado teve a sua acidez acima do padrão desejável na primeira semana, isso porque na segunda semana de armazenamento a acidez calculada em Dornic começou a aumentar exponencialmente. Esse parâmetro de acidez auxilia na determinação da qualidade físico-química do leite, que pode ser influenciada por diversos fatores tais como: saúde das vacas, higiene pré e pós ordenhas, fatores 
Silva, M. A. et al.

nutricionais entre outros (Magalhães, 2005; Araujo et al., 2013).

Quando no teste Dornic a acidez apresenta-se acima de $18^{\circ} \mathrm{D}$, o produto encontra-se fora dos padrões estabelecidos pela vigente legislação brasileira, conhecida como Instrução Normativa 51, o que é sugestivo a falhas em algum dos processos da obtenção do produto, seja na ordenha, manejo, acondicionamento, transporte (Gomes et al., 2011).

Tabela 2 - Valores de acidez nos diferentes métodos de conservação do soro por semana de armazenamento

\begin{tabular}{lcccc}
\hline & \multicolumn{5}{c}{ Acidez } \\
\cline { 2 - 5 } Tipos de conservação & S0 & S1 & S2 & S3 \\
\hline Soro de leite resfriado & $11^{\circ} \mathrm{D}$ & $11^{\circ} \mathrm{D}$ & $16^{\circ} \mathrm{D}$ & $20^{\circ} \mathrm{D}$ \\
Soro de leite pasteurizado & $11^{\circ} \mathrm{D}$ & $17^{\circ} \mathrm{D}$ & $21^{\circ} \mathrm{D}$ & - \\
Soro de leite pasteurizado/congelado & $11^{\circ} \mathrm{D}$ & $22^{\circ} \mathrm{D}$ & - & -
\end{tabular}

Primeira semana do dia 0 do armazenamento do soro (S0); segunda semana de armazenamento do soro para conservação (S1); terceira semana de armazenamento do soro para conservação (S2); quarta semana de armazenamento do soro para conservação (S3).

Cabe ressaltar que logo após a ordenha, o leite não apresenta alterações fermentativas. Essa fermentação ocorre devido à ação da temperatura, que produzirá um fermento e este que será medido pela acidez. Com isso, a perda de leite nas usinas acontecerá quando a fermentação do leite for maior que $18^{\circ} \mathrm{D}$ (Rodrigues et al., 2013).

Quando avaliados os tratamentos em função do ganho de peso $(\mathrm{kg} / \mathrm{dia})$, consumo de ração diário $(\mathrm{kg})$ e conversão alimentar $(\mathrm{kg} / \mathrm{kg})$, houve diferença significativa sobre o ganho de peso $(\mathrm{P}<0,05)$ pelos tratamentos, onde os leitões que foram alimentados com a dieta (D0) sem a presença do soro do leite $(0 \%)$ apresentaram ganho de peso de $0,108 \mathrm{~kg}$. Conforme os níveis de inclusão do soro foram aumentando, foi notória a redução no ganho de peso $0,082,0,081,0,051,0,053 \mathrm{~kg} /$ dia, sendo os respectivos níveis de inclusão $(7 \%, 14 \%, 21 \%$ e $28 \%)$ conforme a (Tabela 3).

Tabela 3 - Valores médios diários de ganho de peso (kg/dia), consumo de ração diário (kg) e conversão alimentar (kg/ $\mathrm{kg}$ ) de leitões alimentados com diferentes níveis de inclusão de soro de leite

\begin{tabular}{lccccc}
\hline \multirow{2}{*}{ Variável } & \multicolumn{5}{c}{ Tratamentos } \\
\cline { 2 - 5 } & D0 & D1 & D2 & D3 & D4 \\
\hline Ganho de peso $(\mathrm{kg} /$ dia) & $0,108 \mathrm{a}$ & $0,082 \mathrm{~b}$ & $0,081 \mathrm{~b}$ & $0,051 \mathrm{c}$ & $0,053 \mathrm{c}$ \\
Consumo de ração diário $(\mathrm{kg})$ & $0,29 \mathrm{c}$ & $0,40 \mathrm{a}$ & $0,31 \mathrm{~b}$ & $0,33 \mathrm{~b}$ & $0,27 \mathrm{c}$ \\
Conversão alimentar $(\mathrm{kg} / \mathrm{kg})$ & $1,53 \mathrm{~d}$ & $1,09 \mathrm{a}$ & $1,18 \mathrm{~b}$ & $1,18 \mathrm{~b}$ & $1,28 \mathrm{c}$ \\
\hline
\end{tabular}

Dieta sem a utilização do soro do leite (D0); Dieta com a substituição de 7\% do soro do leite (D1); Dieta com a substituição de 14\% do soro do leite (D2); Dieta com a substituição de $21 \%$ do soro do leite (D3); Dieta com a substituição de 28\% do soro do leite (D4). *Médias acompanhadas de letras minúsculas distintas apresentam valores estatisticamente diferentes ao nível de $5 \%$.

Em relação ao consumo de ração diário $(\mathrm{kg})$ houve influência $(\mathrm{P}<0,05)$ dos tratamentos, onde o tratamento (D1) com substituição de $7 \%$ do soro do leite apresentou maior consumo $(0,40 \mathrm{~kg})$. Dois tratamentos apresentaram menor consumo diário, o D0 (sem a presença do soro de leite) e o D4 (com o maior nível de substituição $28 \%$ ).

A substituição de 7\% do soro do leite nas dietas proporcionou melhor conversão alimentar quando comparada às demais $(1,09)$, já a pior conversão foi observada no tratamento sem a inclusão do soro nas dietas de suínos.
Em relação ao desempenho dos leitões com a utilização do soro do leite, em um estudo realizado com 48 suínos com idades entre 49 e 63 com a utilização do soro do leite na proporção de 7\%, 14\% e 21\%, leitões do grupo com a suplementação ao nível de $21 \%$ de inclusão apresentaram melhor conversão alimentar, não havendo diferenças entre o ganho de peso entre os tratamentos (Hauptli et al., 2005).

De maneira semelhante, Grinstead et al. (2000) ao comparar a adição do soro na dieta de leitões após o desmame, observou que a inclusão de 7\% melhorou significativamente a conversão alimentar. Fernandes e Miranda (2013) também não observaram diferenças no 
Conservação de soro do leite integral bovino e sua influência na alimentação de leitões na fase de creche

desempenho animal, entretanto, relataram que houve um aumento do consumo do tratamento que utilizou o soro.

Tais resultados corroboram com os apresentados nesta pesquisa, já que os animais dos tratamentos com a adição do soro a 7\% apresentaram melhor conversão alimentar e consumiram mais a dieta. Isto pode ter ocorrido devido ao aumento das quantidades de lactose contida no produto, estes animais nesta fase possuem altos níveis de lactase, além disso, o soro do leite apresenta-se com maior palatabilidade (Bertol et al., 2000b). Ainda de acordo com o autor, esta palatabilidade deve-se ao fato da implantação da fonte de carboidrato mais digestível na dieta destes animais, como a lactose.

De acordo com Brooks et al. (2003) o soro de leite bovino quando fornecido em quantidade adequada tende a influenciar no ganho de peso dos suínos, fazendo com que ocorra uma redução nos custos de produção, por se tratar de um alimento alternativo com custos reduzidos. A substituição de até $30 \%$ por soro do leite integral é capaz de ocasionar resultados de desempenho iguais ou superiores aos efeitos proporcionados pela ração considerada padrão que é composta de milho e soja em suínos nas fases de crescimento-terminação (Bertol et al., 1996a; Navis et al., 2020a).
Além disso, os resultados obtidos no presente estudo corroboram com os citados por Dębiec e Lorenc, (1988), onde os mesmos relataram que o volume de soro incluso na dieta dos suínos pode ter sido um fator limitante para a ingestão das dietas fornecidas que apresentavam maiores teores de matéria seca (MS). Quando avaliado o soro oriundo da produção queijeira, é interessante avaliar os aspectos nutricionais, principalmente no quesito deficiência de compostos tidos como essenciais na nutrição de suínos, mas essa deficiência foi suprida pelos elevados teores de lisina, bem como, lactose, que promoveram melhora na absorção de minerais.

\section{Conclusão}

O melhor método de conservação do soro é mantê-lo resfriado por até uma semana, para melhor aproveitamento do produto já que suas características físico-químicas estão dentro dos padrões previstos em legislação. Dietas para leitões na fase de creche podem ser viáveis quando se utiliza a inclusão do soro em até $7 \%$, pois apesar de aumentar o consumo de ração, se obteve melhorias na conversão alimentar, maximizando o desempenho animal.

\section{Referências}

Almeida, G. R.; Hauschild, L.; Fraga, A. Z.; Oliveira Littiere, T.; Moreira, V. E.; Castro Weitzel, L. C.; Campos, P. H. R. F. 2020. Interaction of space allowance and diet on growth performance and physiological responses of piglets raised in tropical conditions. Tropical Animal Health and Production, 52: 1-8. Doi: https://doi.org/10.1007/s11250-020-02394-4.

Almeida, K. N.; Alvim, T. D. C.; Souza, A. R. M.; Lacerda, G. E.; Alvim, F. A. L. S.; Alvim, J. C. 2015. Enzymatic hydrolysis of lactose of whey permeate. Revista do Instituto de Laticínios Cândido Tostes, 70: 55-63. Doi: https://doi.org/10.14295/2238-6416.v70i2.363.

Araujo, A. P.; Oliveira, V. J.; Siqueira, J. V. M.; Mousquer, C. J.; da Freiria, L. B.; Silva, M. R.; Ferreira, V. B.; Silva Filho, A. S.; de Souza Santos, C. M. 2013. Qualidade do leite na bovinocultura leiteira. PUBVET, 7: 2189-2326. Disponível em: http://www.pubvet.com.br/artigo/787/ qualidade-do-leite-na-bovinocultura-leiteira.

Barros, D. S.; Valentim, J. K.; Medeiros, S. L. D. S.; Faria, S. R.; Pereira, I. D. B.; Pietramale, R. T. R.; Garcia, R. G. 2020. Vinasse in the diet of lactating sows and its effect on litter. Acta Scientiarum. Animal Sciences, 42: 1-6. Doi: https://doi.org/10.4025/actascianimsci.v42i1.48152.

Bertol, T. M.; Ludke, J. V.; Mores, N. 2000b. Efeito de diferentes fontes protéicas sobre desempenho, composição corporal e morfologia intestinal em leitões. Revista Brasileira de Zootecnia, 29: 1735-1742. Doi: https:// doi.org/10.1590/S1516-35982000000600020.

Bertol, T. M.; Santos Filho, J. D.; Bonett, L. 1996a. Soro de leite integral na alimentação dos suínos. Embrapa Suínos e Aves.

Brooks, P. H.; Beal, J.; Niven, S.; Demeckova, V. 2003. Liquid feeding of pigs 2. Potential for improving pig health and food safety. In The IV Conference on effect of genetic and non-genetic factors on carcass and meat quality of pigs, 21: 7-22. Disponível em: https://www.researchgate. net/publication/233324685_Liquid_feeding_of_pigs_II_Potential_for_ improving_pig_health_and_food_safety.
Caldara, F. R.; Rosa, P. S. G.; Oliveira Reis, N. M.; Garcia, R. G.; Almeida, F. A. 2009. Alho e orégano como substitutos de antimicrobianos na alimentação de leitões desmamados. Agrarian, 2: 142-152. Disponível em: https://ojs.ufgd.edu.br/index.php/agrarian/article/view/811/491.

Dębiec, H.; Lorenc, R. 1988. Influence of lactose on phosphate metabolism in rats. British Journal of Nutrition, 59: 87-92. Doi: https:// doi.org/10.1079/BJN19880013.

Fernandes, A.; Miranda, A. P. 2013. Desempenho e ocorrência de diarreia em leitões alimentados com soro de leite. Archivos de zootecnia, 62: 589-594. Doi: http://dx.doi.org/10.4321/S0004-05922013000400011.

Ganju, S.; Gogate, P. R. 2017. A review on approaches for efficient recovery of whey proteins from dairy industry effluents. Journal of Food Engineering, 215: 84-96. Doi: https://doi.org/10.1016/j. jfoodeng.2017.07.021.

Garrido, B. C.; Souza, G. H.; Lourenço, D. C.; Fasciotti, M. 2016. Proteomics in quality control: Whey protein-based supplements. Journal of proteomics, 147: 48-55. Doi: https://doi.org/10.1016/j. jprot.2016.03.044.

Gomes, D. I.; Alves, K. S.; Oliveira, L. R. S.; Véras, R. M. L.; Barcelos, S. S.; Barbosa, C. V. 2011. Qualidade do leite bovino oriundo de diferentes propriedades rurais na região sudeste do Pará, Brasil. Revista de Ciências Agrárias Amazonian Journal of Agricultural and Environmental Sciences, 54: 165-171. Doi: https://doi.org/10.4322/rca.2012.011.

Grinstead, G. S.; Goodband, R. D.; Dritz, S. S., Tokach, M. D.; Nelssen, J. L.; Woodworth, J. C.; Molitor, M. 2000. Effects of a whey protein product and spray-dried animal plasma on growth performance of weanling pigs. Journal of Animal Science, 78: 647-657. Doi: https:// doi.org/10.2527/2000.783647x. 
Silva, M. A. et al.

Haraguchi, F. K.; Abreu, W. C. D.; Paula, H. D. 2006. Proteínas do soro do leite: composição, propriedades nutricionais, aplicações no esporte e benefícios para a saúde humana. Revista de nutrição, 19: 479-488. Doi: https://doi.org/10.1590/S1415-52732006000400007.

Hauptli, L.; Lovatto, P. A.; Silva, J. H. S. D.; Garcia, G. G.; Brum Júnior, B. D. S.; Oliveira, J. L. S. D. 2005. Níveis de soro de leite integral na dieta de leitões na creche. Ciencia rural, 35: 1161-1165. Doi: https:// doi.org/10.1590/S0103-84782005000500027.

Magalhães, A. C. M.; Obtenção higiênica e parâmetros de qualidade do leite de cabra. Viçosa-MG, 2005. Disponível em: https://www.dti. ufv.br/dzo/caprinos/artigos_tec/hig_quali.pdf.

Matalanis, A.; Decker, E. A.; McClements, D. J. 2012. Inhibition of lipid oxidation by encapsulation of emulsion droplets within hydrogel microspheres. Food Chemistry, 132: 766-772. Doi: https://doi. org/10.1016/j.foodchem.2011.11.034.

Navis, M.; Muncan, V.; Sangild, P. T.; Møller Willumsen, L.; Koelink, P. J.; Wildenberg, M. E.; Abrahamse, E.; Thymann, T.; Elburg, R. M. V.; Renes, I. B. 2020a. Beneficial effect of mildly pasteurized whey protein on intestinal integrity and innate defense in preterm and near-term piglets. Nutrients, 12:1125 b. Doi: https://doi.org/10.3390/nu12041125.

Navis, M.; Schwebel, L.; Soendergaard Kappel, S.; Muncan, V.; Sangild, P. T.; Abrahamse, E.; Aunsholt, L.; Thymann, T.; Elburg, R. M. V.; Renes, I. B. 2020b. Mildly pasteurized whey protein promotes gut tolerance in immature piglets compared with extensively heated whey protein. Nutrients, 12: 3391 a. Doi: https://doi.org/10.3390/nu12113391.

Rodrigues, E.; Castagna, A. A.; Dias, M. T.; Aronovich, M. 2013. Qualidade do leite e derivados: processos, processamento tecnológico e índices. Governo do estado do Rio de Janeiro, Niterói, Programa Rio Rural. 53p. (Manual Técnico, 37).
Rostagno, H. S.; Albino, L. F. T.; Donzele, J. L.; Gomes, P. C.; Oliveira, R. D.; Lopes, D. C.; Ferreira, A. S.; Barreto, S. D. T. 2011. Tabelas brasileiras para aves e suínos. Composição de alimentos e exigências nutricionais. 3. ed. Editora UFV. Viçosa, MG.

Rosa, P. P.; Zanela, M. B.; Ribeiro, M. E. R.; Fluck, A. C.; Angelo, I. D. V.; Ferreira, O. G. L.; Costa, O. A. D. 2017. Fatores etiológicos que afetam a qualidade do leite e o Leite Instável Não Ácido (LINA). REDVET. Revista Electrónica de Veterinaria, 18: 1-17. Disponível em: http:// www.veterinaria.org/revistas/redvet/n121217.html.

Santos, D. B.; Aguiar, R. O.; da Cruz, W. P.; da Silva Bernardino, P. D. L.; da Silva Martins, L. H.; Carvalho, F. I. M.; Bichara, C. M.G; Silva, P. A. 2020. Desenvolvimento e caracterização de doces de leite bubalino pastosos saborizados com doces de bacuri e Cupuaçu. Brazilian Journal of Development, 6: 56917-56935. Doi: https://doi.org/10.34117/ bjdv6n8-195.

Sugiharto, S.; Lauridsen, C.; Jensen, B. B. 2015. Gastrointestinal ecosystem and immunological responses in E. coli challenged pigs after weaning fed liquid diets containing whey permeate fermented with different lactic acid bacteria. Animal Feed Science and Technology, 207: 278-282. Doi: https://doi.org/10.1016/j.anifeedsci.2015.06.019.

Xiao, K.; Jiao, L.; Cao, S.; Song, Z.; Hu, C.; Han, X. 2016. Whey protein concentrate enhances intestinal integrity and influences transforming growth factor- $\beta 1$ and mitogen-activated protein kinase signalling pathways in piglets after lipopolysaccharide challenge. British Journal of Nutrition, 115: 984-993. Doi: https://doi.org/10.1017/ S0007114515005085.

Zardo, A. O.; de LIMA, G. J. M. M. 1999. Alimentos para suínos. Embrapa Suínos e Aves- Livro técnico (INFOTECA-E). 